\title{
Second trimester spontaneous rupture Uterus, unusual case, Case report and review of literature
}

\author{
Shereen Ibrahim ${ }^{1}$ \\ ${ }^{1}$ Affiliation not available
}

May 5, 2020

"Second trimester spontaneous rupture Uterus, unusual case: Case report and review of literature".

Shereen Ibrahim, MBBCH, MSC, MRCOG, North Middlesex University Hospital, Obstetrics and Gynaecology department.

Corresponding author: Shereen Ibrahim, London, N9 9RT, 07502335191, Ibrahim.shereen@nhs.net

\section{Introduction:}

Uterine rupture is a serious obstetric complication that occurs mainly in the third trimester of pregnancy or during labour, especially in previously scarred uterus. Advanced maternal age, grand multiparous, placenta increta, macrosomia, shoulder dystocia, and medical termination of pregnancy are some contributing factors to uterine rupture. The overall incidence of uterine rupture in unscarred uterus is $0.5-2$ per 10000 deliveries, The risk of scar rupture after one caesarean section is one in 200 women with spontaneous births.(1)

Uterine rupture in the first or second trimester of pregnancy is extremely rare, and may vary in presentation and course of events, which make the clinical diagnosis challenging. These may be masked by the physiological and anatomical changes during pregnancy. The lack of high index of suspicion diverts attention to search for other non-gynaecological problems.(2) Unlike rupture in the lower uterine segment in the third trimester or during delivery, the common site of rupture in the first trimester is the fundal region. $(3,4)$

Case Report:

A 28 year-old woman, gravida 4 , para $2+1$ who was16 weeks pregnant presented with a sudden onset of epigastric pain that radiated to her back following a fall. Her first pregnancy was a caesarean delivery for term breech presentation followed by two successful vaginal deliveries. She had one first trimester miscarriages which had been surgically managed.

On presentation, her vital sgins was stable and was admitted under observation and pain management. However she started to deteriorate clinically, became tachycardia 120/min and hypotensive 90/50. She also reported shoulder tip pain and shortness of breath.

On examination, patient looked pale; her abdomen was distended and peritonitic. A bedside ultrasound showed single viable intrauterine pregnancy and large amount of free fluid in the abdomen. Consultant informed and surgical team involved. Decision taken to proceed to theatre and patient consented for midline exploratory laparotomy +/- proceed. Her hemoglobin on VBG was $4 \mathrm{gm} \%$.

Intraoperatively haemoperitoneum of 2 liters of fresh blood and clots noted. The stomach, liver, spleen, kidneys, and major vessels were normal. There was a rupture of the uterine fundus

Second trimester spontaneous rupture Uterus 
measuring $6 \times 4 \mathrm{~cm}$, exposing the amniotic membrane with alive feotus (300 gm) and placenta. In addition multiple $1 \mathrm{~cm}$ defects seen in the posterior wall of the uterus. Cesarean section scar was intact.

The uterus was sutured in three layers, as the patient was not consented for hysterectomy. Four units of blood transfused in theatre. Postoperatively, patient debriefed, advised against further pregnancies in view of risk of recurrent rupture and was scheduled for tubal sterilization.

\section{Discussion:}

Clinical signs of uterine rupture in early pregnancy are nonspecific and must be distinguished from acute abdominal emergencies. Abdominal pain, vaginal bleeding, and vomiting are classic findings. Differential diagnoses are bleeding corpus luteum, heterotropic pregnancy, and other surgical causes of acute abdomen(6).

Sometimes ultrasound has limited value and urgent surgery is necessary to prevent catastrophic sequelae. An emergency laparoscopy or laparotomy is needed for the correct diagnosis and to enable the necessary treatment to take place. Early proper management are necessary to decrease the high maternal and fetal mortality and morbidity rates associated with uterine rupture. In our case, the diagnosis was not clear. We performed emergency laparotomy after judging that laparoscopic instrumentation was deficient because of the unstable vital signs of the patient. Early surgical intervention is usually the key to successful treatment of uterine rupture.

Few cases cited in the literature were diagnosed after postmortem on autopsy. The clinicians were misled by the ultrasound finding of an intrauterine pregnancy, and searched for other non-gynaecological causes which delayed the management. (5)

Clinicians, especially first liners, should be aware of anatomical changes in pregnancy as the uterus is enlarged and becomes an abdominal organ. In evaluating pregnant lady, mild abdominal pain or discomfort may be acceptable, but severe sudden pain associated with vomiting, sign of peritoneal irritation, and possible obstetric etiology should be considered seriously.(7)

No conflict of interests to be declared.

Funding: Not applicable.

Patient's consent for permission to publication was obtained verbally.

Author: SI, clinician involved in patient care, literature review, main author.

\section{References:}

1. Smith JF, Wax JR. UpToDate; 2013. Rupture of the unscarred uterus. [Internet] Available from: www.uptodate.com

2. Arbab F, Boulieu D, Bied V, Payan F, Lornage J, Guerin JF. Uterine rupture in first or second trimester of pregnancy after in-vitro fertilization and embryo transfer. Hum Reprod . 1996;11(5):1120-1122.

3. Park YJ, Ryu KY, Lee JI, Park M. Spontaneous Uterine Rupture in the First Trimester: A case Report. J Korean Med Sci . 2005;20(6):1079-1081.

4. Schrinsky DC, Benson RC. Rupture of the pregnant uterus: a review.Obstet Gynecol Surv . 1978;33(4):217-232.

5.Dalia F. ABDULWAHAB, Hamizah ISMAIL, Zalina NUSEE. Second-Trimester Uterine Rupture: Lessons Learnt. Malays J Med Sci. 2014 Jul; 21(4): 61-65.

6. S. Ijaz, A. Mahendru, and D. Sanderson, "Spontaneous uterine rupture during the 1st trimester: a rare but life-threatening emergency," Journal of Obstetrics and Gynaecology, vol. 31, no. 8, p. 772, 2011.

7. Kilpatrick CC, Orejuela FJ. United States (US): Wolters Kluwer Health; 2013. Approach to abdominal pain and the acute abdomen in pregnant and postpartum women. [Internet] Available from: 
www.uptodate.com .

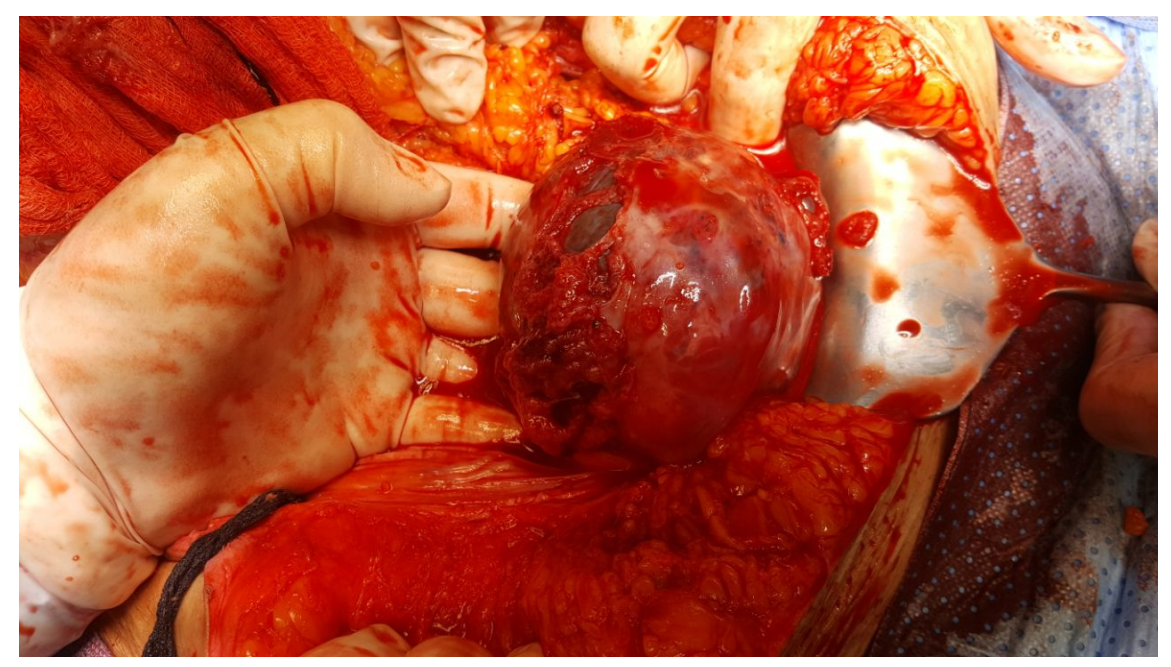




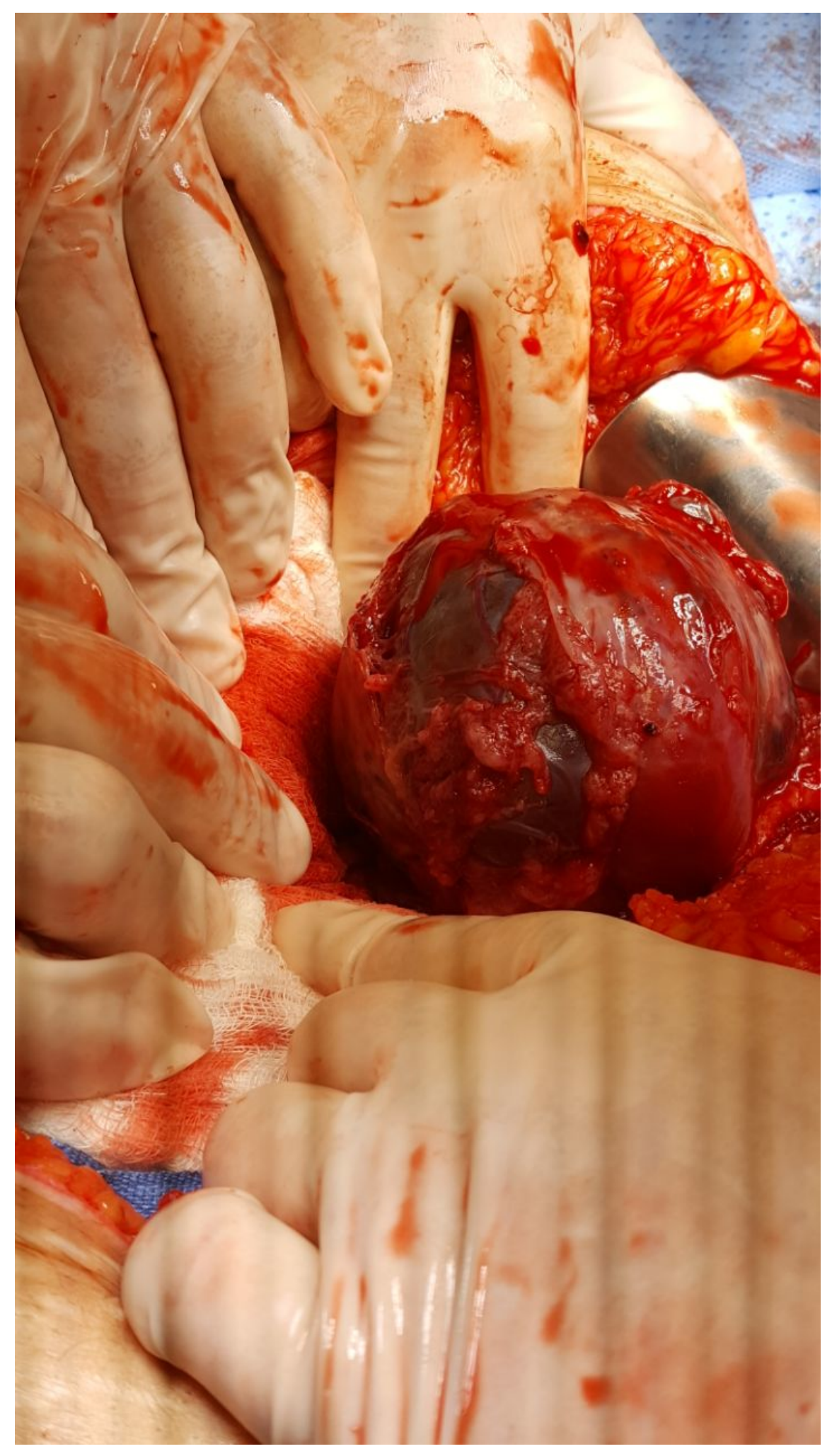




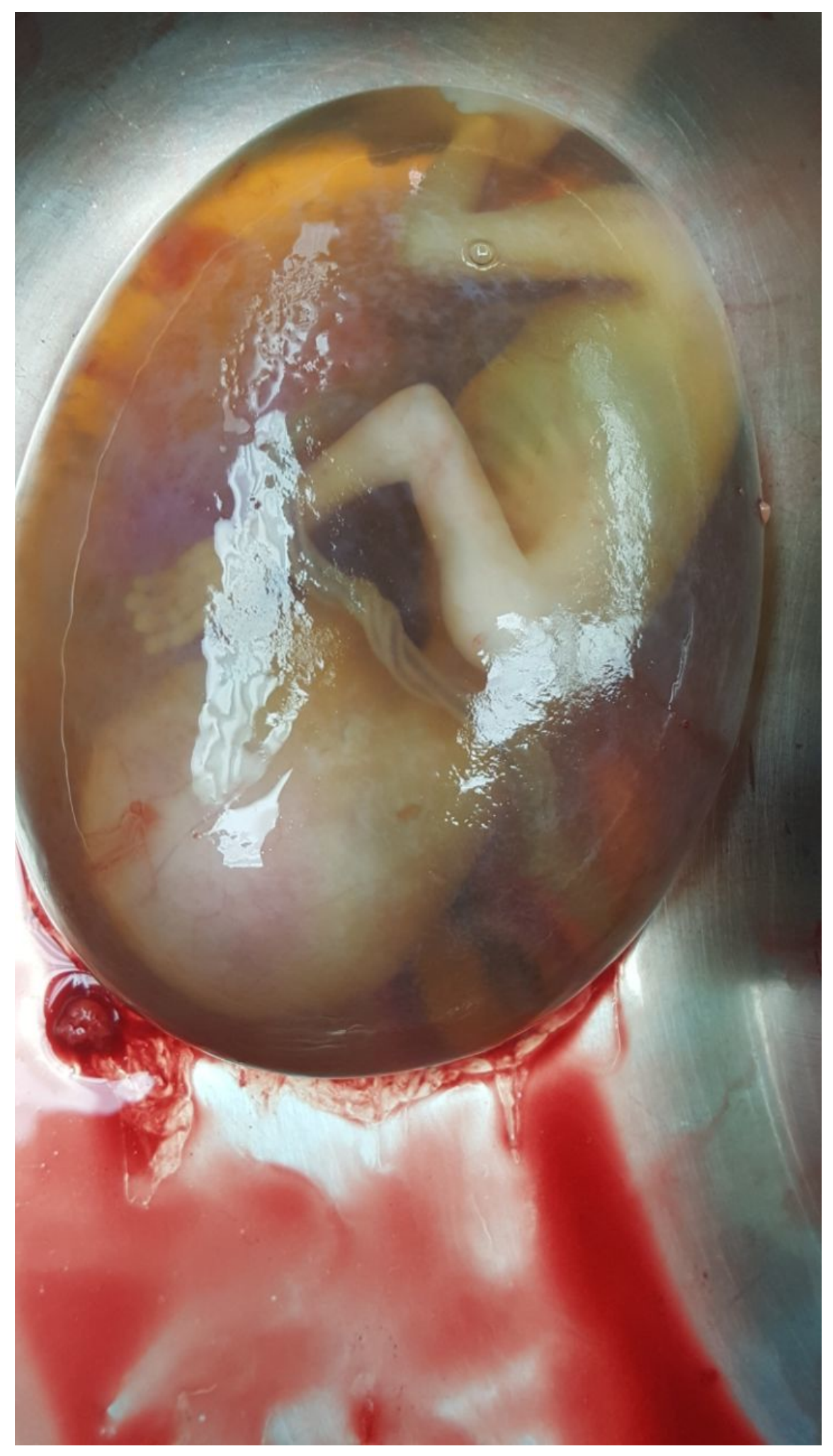

